http://jmscr.igmpublication.org/home/ ISSN (e)-2347-176x ISSN (p) 2455-0450 crossref DOI: https://dx.doi.org/10.18535/jmscr/v8i8.54

\title{
Glomus Jugulare and Anaesthetic Implications- A Case Report
}

\author{
Authors \\ Hally. ${ }^{1}$, Soumya $\mathbf{C N}^{2 *}$, Praveen Rajendran ${ }^{3}$, Sudha $\mathbf{P}^{4}$ \\ ${ }^{1}$ Senior Resident, Department of Anaesthesiology, Regional Cancer Centre, Trivandrum \\ ${ }^{2,3}$ Postgraduate Student, Department of Anaesthesiology, Regional Cancer Centre, Trivandrum \\ ${ }^{4}$ Additional Professor, Department of Anaesthesiology, Regional Cancer Centre, Trivandrum \\ *Corresponding Author \\ Soumya CN
}

\section{Abstract}

Glomus tumors are rare but locally aggressive, vascular paragangliomas of the skull base. These tumors may progress to cause lower cranial nerve palsies and may involve the major vascular structure in the skull base. We are reporting one of these cases and the anaesthetic challenges involved in the management of this case.

\section{Introduction}

Glomus tumors are paragangliomas, which are tumors of neural crest origin, outside the adrenal medulla capable of secreting catecholamines in autonomic ganglia, the Organ of Zuckerkandl, or adjacent to ganglia. ${ }^{(1)}$ Glomus tumors are uncommon, accounting for only $0.03 \%$ of all neoplasms and $0.6 \%$ of head and neck tumors. ${ }^{(2)}$ Clinical manifestations depend upon tumor location. These relate most often to the middle ear and cranial nerve dysfunction. Pulsatile tinnitus, conductive hearing loss, aural fullness, discharge or bleeding, and a bluish-red mass behind the tympanic membrane are characteristic of the former. Facial paralysis, dysphonia, marked hearing loss, and pain typify the latter. ${ }^{(3)}$ Aural symptoms will appear first followed by neural symptoms. Anaesthetic challenges include excess catecholamine or serotonin secretion by the tumor cells, the involvement of cranial nerves that may predispose to airway obstruction or aspiration, and delayed gastric emptying. Other concerns are maintenance of normal intracranial pressure (ICP), air or tumorembolism, substantial blood loss and management of postoperative nausea and vomiting (PONV).

\section{Case Report}

We are reporting a case of 47 years old, $50 \mathrm{~kg}$ Indian gentleman who presented with left-sided tinnitus, aspiration, hoarseness of voice, and difficulty in swallowing of six-month duration. On examination facial nerve was clinically intact, the tongue was deviated towards left, left hypoglossal nerve palsy, and left palatal palsy were present. Seventy-degree scopy showed left vocal cord palsy. He was having lower cranial nerve palsy (VIII, IX, X, XII) of left side. MRI showed a lesion with salt and pepper appearance involving left IJV, jugular bulb, sigmoid sinus, reaching up to jugular foramen, meso tympanum, and hypotympanum, suggestive of glomus jugulare. 
The patient was planned for surgical removal of the tumor. Preoperative embolization of the tumor was done by an interventional radiologist. On preanesthetic check-up, he was found to have elevated TSH levels and T. Eltroxin $75 \mathrm{mcg}$ was started and thyroid status was optimized. He was screened for urinary VMA and found to be normal. But his blood pressures showed fluctuating values, which could be due to the close proximity of the tumor to the carotid body.

After obtaining written informed consent from patient and his relative, we planned to do the procedure under general anesthesia and controlled ventilation with modified rapid sequence induction. The patient was premedicated with $\mathrm{T}$. Pantoprazole $40 \mathrm{mg}$ and T. Metoclopramide10mg, T.Alpraxolam $0.5 \mathrm{mg}$ on preoperative day and morning of surgery. As soon as the patient was shifted for surgery to the operation table he was pre medicated with Inj. Midazolam $1 \mathrm{mg}$, inj.fentanyl $50 \mathrm{mcg}$, Inj Dexona $12 \mathrm{mg}$, and preoxygenated with $100 \%$ oxygen. Anesthesia was induced with Propofol 100mg, additional dose of fentanyl $50 \mathrm{mcg}$.Nasal intubation was facilitated with muscle relaxant vecuronium $(0.1$ $\mathrm{mg} / \mathrm{kg}$ ) intravenously. Maintenance anesthesia consisted of intermittent positive pressure ventilation with air oxygen mixtures of $\mathrm{FiO}_{2} 45 \%$ and sevoflurane at 0.8 to 1.0MAC. The patient was positioned for surgery by placing a small pillow under the shoulder and turned the head to the opposite side of the lesion. Plane of anesthesia maintained with Dexmedetomidine infusion at 1020 mcg per hour. Patient was monitored intraoperatively with standard ASA monitors, invasive blood pressure, cardiac output monitor and Bispectral index (BIS). Intraoperative hemodynamic profile maintained with goaldirected fluid therapy using cardiac output monitoring. BP fluctuations controlled by intermittent nitroglycerine infusion 5 to $15 \mathrm{mcg}$ /min. MAP was maintained between 60-65 and a core temperature of around $35^{\circ} \mathrm{C}$ during the procedure. Forced-air warmer was applied to prevent hypothermia. The duration of the surgery was $11 \mathrm{hrs}$. Intraoperatively AB G was analyzed and showed within normal limits. We decided to keep the nasotracheal tube to prevent aspiration in the immediate post-operative periods. After attaining spontaneous respiration, neuromuscular blockade was reversed with $2.5 \mathrm{mg}$ neostigmine with $0.4 \mathrm{mg}$ glycopyrrolate. Inj morphine $3 \mathrm{mg}$ IV was given. For prevention of postoperative vomiting inj.Ondansetrone was given 30 minutes before the reversal, IV. dexamethasone $12 \mathrm{mg}$ eighth hourly, IV. Ondansetrone $8 \mathrm{mg}$ eighth hourly and inj Stemitil $12.5 \mathrm{mg}$ IM eighth hourly were added in the post-operative orders. While shifting to ICU the patient was conscious and tolerating the tube well and his vitals remained stable. The patient was extubated on the next day morning under supervision. The patient was symptomatically better and not had even a single episode of vomiting.

\section{Discussion}

Glomus tumors are rare locally aggressive benign vascular paragangliomas of the skull base. The growth of these can produce lower cranial nerve palsies and may involve the major vascular structures of the skull base. Carotid body tumors account for $60 \%$ of head and neck paraganglioma and the rest include glomus jugulare, vagale, and tympanicum ${ }^{(4)}$. Anaesthetic challenges involved are excess catecholamine or serotonin secretion by the tumor cells, the involvement of cranial nerves that may predispose to airway obstruction or aspiration, delayed gastric emptying associated with these type of tumors, management of intracranial hypertension (ICP), air or tumor embolism, and management of postoperative nausea and vomiting (PONV). Only $1-4 \%$ of glomustumors mimic pheochromocytoma by secreting catecholamines. ${ }^{(5)}$ But all of them should be screened and optimized. Intraoperatively, histamine, and bradykinin released during surgical manipulation can cause severe hypotension and even shock. Severe hypertension is of particular concern. 5-Hydroxytryptamine may increase vascular response to catecholamines by 
stimulating the release and inhibiting the uptake of noradrenaline and potentiating post junctional $\alpha-1$ adrenoceptor mediated response to both epinephrine and norepinephrine. Anaesthetic management in the setting of intracranial hypertension secondary to tumor extension should follow the same general principles as for other intracranial mass lesions ${ }^{(6)}$ Strict precautions need to be taken to control intracranial pressures. The risk of venous air embolism is high in these surgeries, so precautions are to be taken and we can use transesophageal echo for early detection of venous thromboembolism.

\section{Conclusion}

Glomus tumors are paragangliomas of the head and neck and they present with multiple and challenging anaesthetic risks. Clinical manifestations depend upon tumor location but most often relate to the middle ear and cranial nerve dysfunction. The treatment is surgical removal because of the increased effectiveness of preoperative imaging and tumor mapping with the CT and 3D-CT scans, MR imaging, angiography, and magnetic resonance angiography. Anaesthetic risk includes catecholamine secretion producing symptoms of a pheochromocytoma, serotonin secretion producing symptoms of carcinoid syndrome, aspiration following tumor resection, impaired gastric emptying, increased intracranial pressure, the threat of venous air embolism, and substantial blood loss. Of the many significant recent developments adding to the understanding of these lesions, the recognition that they may predispose to gastroparesis and new concepts concerning the testing for and treatment of catecholamine and serotonin excess is perhaps most important to the anaesthesiologist.

\section{Conflicts of Interest: Nil}

Funding: Nil

Acknowledgement: Patient and his relatives for consent.

\section{References}

1. Kremer R, Michel RP, Posner B, Wang NS, Lafond GP, Crawhall JC. Catecholamine secreting paraganglioma of glomusjugulare region. Am J Med Sci 1989; 297: 46-48

2. Boyle JO, Shimm DS, Coulthard SW. Radiation therapy for paragangliomas of the temporal bone. Laryngoscope 1990; 100: 896-901.

3. Bundgaard $\mathrm{T}$, Tandrup $\mathrm{O}$, Elbrond $\mathrm{O}$, Nordentoft AM. Treatment of glomustumors. A retrospective survey. Clin Otolaryngol 1989; 14: 155-60.

4. Shyamkumar.S,AlokThakar,Complexglom usjugularetumor:managementissues.Indian

J Otolaryngol Head Neck Surg,2013; 65,S676-81

5. Jackson CG, Harris PF, Glasscock MEI, et al. Diagnosis and management of paragangliomas of the skull base. Am J Surg 1990; 159: 389-93

6. Shapiro HM, Drummond JC. Neurosurgical anesthesia and intracranial hypertension. In: Miller R. D., ed. Anesthesia. New York: Churchill Livingstone, 1990; 1737-98. 